\section{A stimulatory phalloid organ in a weaver bird}

The males of very few bird species possess a penis $^{1}$. Buffalo weavers, Bubalornis spp., are unique in possessing a false penis, or phalloid organ ${ }^{2,3}$. We find that, after protracted copulation, the phalloid organ generates an orgasm-like state in males, a phenomenon not known in any other bird. The possession of a phalloid organ and orgasm may be associated with the buffalo weaver's unusual mating system in which there is intense sperm competition.

We studied individually colour-ringed red-billed buffalo weavers, B. niger (Fig. 1a), in Namibia. The phalloid organ is a stiff rod of connective tissue $15.7 \pm 0.29$ (s.e.) $\mathrm{mm}$ long $(n=109)$ that lies immediately anterior to the cloaca (Fig. 1b). It has no ducts ${ }^{2,3}$ and is not homologous to any penis found in any other bird species ${ }^{1}$. Females have a much smaller phalloid organ $(6.1 \pm 0.19$ mm long, $n=68$ ).
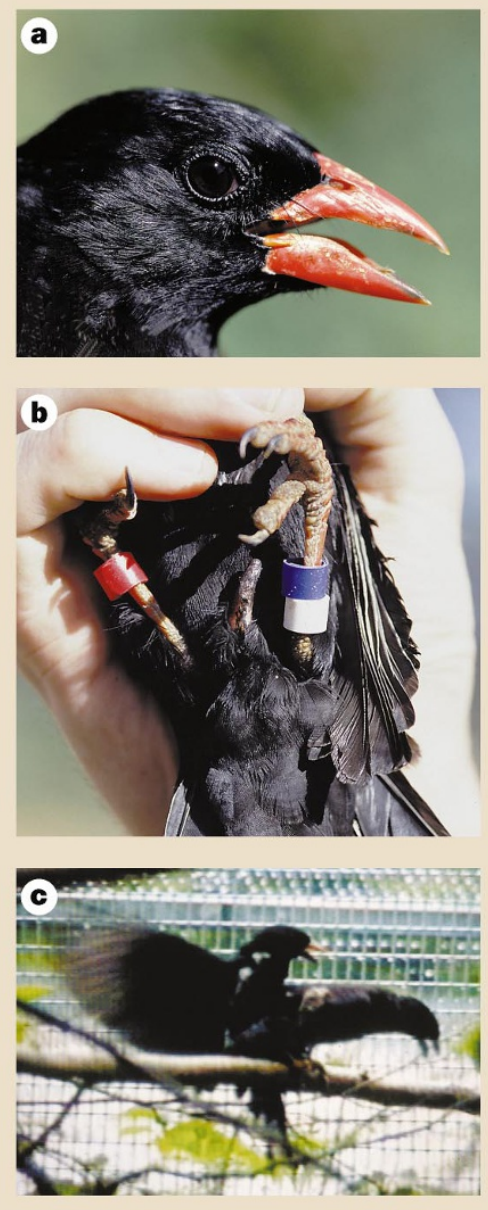

Figure 1 Buffalo weavers, Bubalornis niger, have a false penis, or phalloid organ. a, Head of a male buffalo weaver. b, A male held to show the phalloid organ. c, A pair of captive buffalo weavers copulating.
The buffalo weavers bred in colonies of $5.7 \pm 1.1$ nests $(n=24)$, with each nest containing $6.5 \pm 0.8 \quad(n=16)$ chambers, of which $4.6 \pm 0.7(n=13)$ were occupied by a single female. Of ten nests studied, two were defended by one male, and eight by two males who appeared to operate as a coalition: both males built the nest, defended it against other males, and fed the chicks in all nest chambers. The mating system was therefore either polygyny or, at two-male nests, cooperative polygynandry.

Multilocus DNA fingerprinting ${ }^{4}$ of ten male coalitions revealed that in only one instance were males probably first-order relatives (brothers, or father and son); in at least seven other cases, coalition males appeared to be completely unrelated. Sperm competition was intense. Multilocus DNA fingerprinting of 55 offspring from 25 broods indicated that, in 18 broods (72\%), offspring either had more than one father or included offspring fathered by non-resident males.

Copulations were difficult to observe because they occurred between 75 and 500 metres from the nest in dense tree cover. Six complete sequences were protracted (mean $18.0 \mathrm{~min}$, range $4-30 \mathrm{~min}$ ) and comprised alternating sequences of 'bouncing' displays by both sexes and mounting. It was impossible to establish the position or role of the phalloid organ during copulation as it was obscured by feathers. We therefore caught (under licence) 13 males and 6 females, transported them to Germany and kept them in aviaries, where we observed 57 copulations between three males and five females. In captivity, males also copulated 34 times with a taxidermist's mounted female with an artificial cloaca ${ }^{5}$ (a 'model female'), which we placed inside the aviary.

Mounting was similar to that in other birds, with the male on the female's back. But as copulation proceeded, the male usually adopted a reclining position, leaning backwards away from the female (Fig. 1c). Contrary to earlier speculation ${ }^{1,3}$, the phalloid organ was not intromittent, but instead appeared to be rubbed against the female's cloacal region. As in the wild, mounting bouts were prolonged $(29.0 \pm 0.76 \mathrm{~min}$, $n=34$ ). In the final stages of copulation, males appeared to experience an orgasm during which the male's wing beat slowed to a quiver and his entire body shook; with his leg muscles apparently in spasm, his feet clenched hold of the female and drew her towards him. The behaviour of males copulating with the model female was similar, and only in those instances when males experienced an orgasm $(n=34)$ was semen found in the false cloaca, suggesting that orgasm is necessary for ejaculation.

To test the idea that protracted mounting and physical stimulation of the phalloid organ results in orgasm and ejaculation, we rubbed the phalloid organ of each of three males (on two separate occasions each) immediately after they had copulated with and inseminated a live female. All three ejaculated almost immediately each time; similar stimulation without mounting was ineffective.

Our results indicate that the phalloid organ is a stimulatory organ that may have evolved in response to the intense sperm competition mediated, in part, by a polygynandrous mating system. Unusual copulation behaviour occurs in other birds with intense sperm competition ${ }^{6,7}$. The way in which a stimulatory phalloid organ increases male reproductive success remains unclear, however. One possibility is that, as in some rodents ${ }^{8}$, repeated mounting and protracted physical stimulation of the male, and consequently the female, before ejaculation increases the likelihood that a female will retain and utilize his sperm.

M. Winterbottom, T. Burke, T. R. Birkhead Department of Animal and Plant Sciences,

University of Sheffield,

Western Bank, Sheffield S10 2TN, UK

e-mail: t.r.birkhead@sheffield.ac.uk

\footnotetext{
. King, A. S. in Form and Function in Birds (ed. King, A. S. \& McLelland, J.) 107-147 (Academic, London, 1981).

2. Bentz, G. D. Auk 100, 501-504 (1983).

3. Birkhead, T. R., Stanback, M. T. \& Simmons, R. E. Ibis 135, 326-331 (1993).

4. Burke, T. \& Bruford, M. W. Nature 327, 149-152 (1987).

Pellatt, E. J. \& Birkhead, T. R. Ibis 136, 97-101 (1994).

6. Davies, N. B. Dunnock Behaviour and Social Evolution (Oxford Univ. Press, 1992).

Schulze-Hagen, K., Leisler, B., Birkhead, T. R. \& Dyrcz, A. Ibis 137, 85-91 (1995).

8. Matthew, M. K. \& Adler, N. T. Physiol. Behav. 20, 303-309 (1978).
}

\section{Green processing using ionic liquids and $\mathrm{CO}_{2}$}

Many organic solvents evaporate into the atmosphere with detrimental effects on the environment and human health. But roomtemperature ionic liquids, with low viscosity and no measurable vapour pressure ${ }^{1}$, can be used as environmentally benign media for a range of industrially important chemical processes ${ }^{2-6}$, despite uncertainties about thermal stability and sensitivity to oxygen and water. It is difficult to recover products, however, as extraction with water ${ }^{7}$ works only for hydrophilic products, distillation is not suitable for poorly volatile or thermally labile products, and liquid-liquid extraction using organic solvents results in crosscontamination. We find that non-volatile organic compounds can be extracted from ionic liquids using supercritical carbon dioxide, which is widely used to extract large organic compounds with minimal pollution ${ }^{8}$. Carbon dioxide dissolves in the liquid to facilitate extraction, but the ionic 


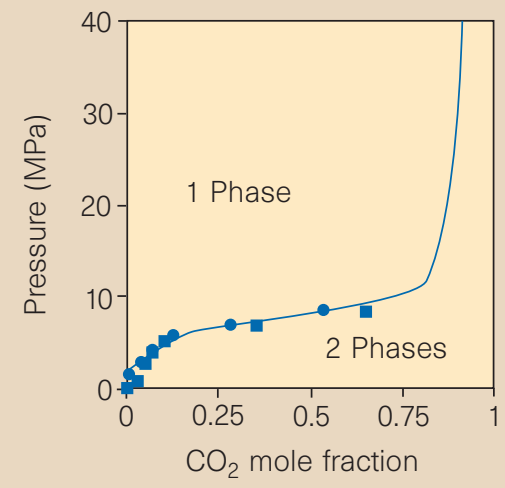

Figure 1 Phase diagram for the $\mathrm{CO}_{2}-[\mathrm{BMIM}][\mathrm{PF} 6]$ system. $\mathrm{CO}_{2}$ solubility in the ionic liquid-rich liquid phase at $\mathrm{CO}_{2}$ mole fractions up to 0.75 was determined using a high-pressure view cell ${ }^{\text {t1 }}$ rated to 8.3 $\mathrm{MPa}$. The number of moles of $\mathrm{CO}_{2}$ in the liquid phase at a given temperature and pressure was determined by difference, using IUPAC pure $\mathrm{CO}_{2}$ density data ${ }^{12}$ to obtain the number of moles of $\mathrm{CO}_{2}$ in the vapour phase (assumed to be pure $\mathrm{CO}_{2}$ ). Cloud points of dilute mixtures (1.3-7.2\% ionic liquid) were determined using a variable-volume view cell ${ }^{13}$ rated to $40 \mathrm{MPa}$. The solubility of the ionic liquid in the $\mathrm{CO}_{2}$-rich phase was checked with an ISCO 220SX high-pressure extraction apparatus. A small quantity of ionic liquid was loaded onto a polyurethane foam sponge and extracted with $\mathrm{CO}_{2}$ at $13.8 \mathrm{MPa}$ and $40{ }^{\circ} \mathrm{C}$. The saturated $\mathrm{CO}_{2}$ phase leaving the system was depressurized through a heated restrictor and slowly bubbled through a flask of ethanol. Ultraviolet and visual absorption of the collection solvent was used to determine that no ionic liquid was extracted. The circles and squares indicate two separate, replicate experiments.

liquid does not dissolve in carbon dioxide, so pure product can be recovered.

We synthesized ${ }^{7}$ the ionic liquid 1-butyl3-methylimidazolium hexafluorophosphate [BMIM][PF6], which is stable in the presence of either oxygen or water. Our primary objective was to show that $\mathrm{CO}_{2}$ could be used to extract naphthalene, our lowvolatility model solute, from an ionic liquid, but it was important to show that the $\mathrm{CO}_{2}$ rich phase is not significantly contaminated by the ionic liquid, as would be expected during contact of $\mathrm{CO}_{2}$ with any conventional organic solvent. We therefore investigated the phase behaviour of [BMIM][PF6] with $\mathrm{CO}_{2}$, as well as with naphthalene, and finally that of the [BMIM] [PF6]- $\mathrm{CO}_{2}-$ naphthalene ternary.

$\mathrm{CO}_{2}$ is highly soluble in [BMIM] $\left.\mathrm{PF} 6\right]$ (Fig. 1), reaching a mole fraction of 0.6 at $8 \mathrm{MPa}$, yet the two phases are not completely miscible: cloud points of mixtures ranging from 1.3 to 7.2 mole $\%$ of ionic liquid at $25^{\circ} \mathrm{C}$ could not be found at pressures up to $40 \mathrm{MPa}$, the highest pressure accessible with our equipment. The composition of the $\mathrm{CO}_{2}$-rich phase is essentially pure $\mathrm{CO}_{2}$. After extracting the ionic liquid with $55 \mathrm{~g}$

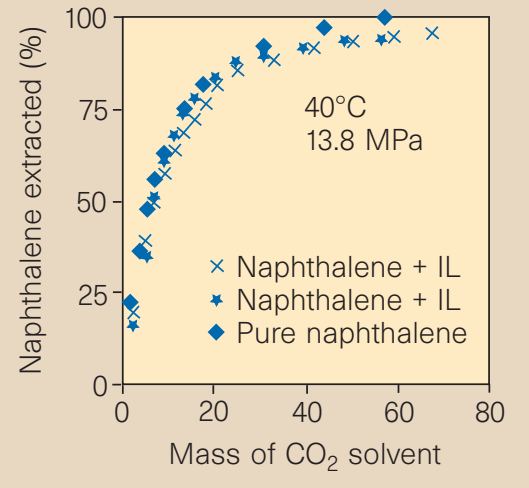

Figure 2 Extraction of naphthalene from the naphthalene/[BMIM][PF6] mixture using $\mathrm{CO}_{2}$ at $40{ }^{\circ} \mathrm{C}$ and 13.8 MPa. The ISCO extractor was the same as that in Fig. 1. The naphthalene concentration in the ethanol collection solution was determined by ultraviolet and visual spectroscopy, using peaks at 267 , 276 and $285 \mathrm{~nm}$. Replicate experiments indicate 96\% recovery (crosses) from a $0.0431 \mathrm{~g}$ sample (containing $0.00265 \mathrm{~g}$ naphthalene) contacted with $67 \mathrm{~g} \mathrm{CO}_{2}$, and 94\% recovery (stars) from a $0.0409 \mathrm{~g}$ sample (containing $0.00252 \mathrm{~g}$ naphthalene) contacted with $56 \mathrm{~g} \mathrm{CO}_{2}$. Data for the dissolution of an equivalent amount of solid naphthalene into $\mathrm{CO}_{2}$, using the same extractor and analytical technique, are also shown (diamonds).

$\mathrm{CO}_{2}$ at $13.8 \mathrm{MPa}$ and $40^{\circ} \mathrm{C}$, there was no detectable [BMIM][PF6] in the extract, indicating that the solubility is less than $10^{-5}$ mole fraction. In contrast, a mixture of $\mathrm{CO}_{2}$ with a conventional organic liquid results in significant solubility of the liquid in the $\mathrm{CO}_{2}$-rich phase. The phase behaviour of the ionic liquid- $-\mathrm{CO}_{2}$ system resembles that of a cross-linked polymer-solvent system ${ }^{9}$, even though [BMIM][PF6] is a lowviscosity, low-molecular-weight liquid. The liquid phase increased in volume by only $10-20 \%$ when $8 \mathrm{MPa}$ of $\mathrm{CO}_{2}$ pressure was applied, perhaps because it is ionic; this corresponds to a more than twofold decrease in the molar volume.

Naphthalene was chosen as our model non-volatile organic solute because it dissolves readily in [BMIM][PF6] (maximum solubility of 0.30 mole fraction at $40{ }^{\circ} \mathrm{C}$ ) and in $\mathrm{CO}_{2}$ (with a solubility of $0.013-0.017$ mole fraction at $35{ }^{\circ} \mathrm{C}$ and pressures of 12.2-20.4 MPa; ref 10). A mixture of 0.12 mole fraction naphthalene in [BMIM][PF6] was extracted with $\mathrm{CO}_{2}$ at $13.8 \mathrm{MPa}$ and $40{ }^{\circ} \mathrm{C}$ with recoveries of 94-96\% (Fig. 2). This near-quantitative recovery compares favourably with the dissolution of a similar amount of pure solid naphthalene with comparable amounts of $\mathrm{CO}_{2}$ (Fig. 2). It is therefore possible to quantitatively extract a non-volatile organic solute from an ionic liquid using $\mathrm{CO}_{2}$ without any contamination. Moreover, the dissolution of $\mathrm{CO}_{2}$ in the ionic liquid is completely reversible: pure ionic liquid remains after extraction of the naphthalene and depressurization.

Lynnette A. Blanchard ${ }^{\star}$, Dan Hancu $\dagger$, Eric J. Beckman $\dagger$, Joan F. Brennecke ${ }^{\star}$

* Department of Chemical Engineering,

University of Notre Dame,

Notre Dame, Indiana 46556, USA

e-mail: jfb@nd.edu

$\dagger$ Department of Chemical Engineering,

University of Pittsburgh,

Pittsburgh, Pennsylvania 15261, USA

1. Seddon, K. R. J. Chem. Tech. Biotechnol. 68, 351-356 (1997)

2. Chauvin, Y. \& Olivier-Bourbigou, H. Chemtech 25, 26-30 (1995)

3. Adams, C. J., Earle, M. J., Roberts, G. \& Seddon, K. R. Chem. Commun. 19, 2097-2098 (1998).

4. Earle, M. J., McCormac, P. B. \& Seddon, K. R. Chem. Commun. 20, 2245-2246 (1998).

5. Earle, M. J., McCormac, P. B. \& Seddon, K. R. Green Chem. 1, 23-25 (1999).

6. Ellis, B., Keim, W. \& Wasserscheid, P. J. Chem. Commun. 4, 337-338 (1999).

7. Huddleston, J. G. et al. Chem. Commun. 16, 1765-1766 (1998).

8. Brennecke, J. F. Chem. Ind. 21, 831-834 (1996).

9. Moerkerke, R. et al. Macromolecules 31, 2223-2229 (1998).

10. Sako, S., Ohgaki, K. \& Katayama, T. J. Supercrit. Fluids 1, 1-6 (1988).

11. Huie, N. C., Luks, K. D. \& Kohn, J. P. J. Chem. Eng. Data 18, 311-313 (1973).

12. Angus, S., Armstrong, B. \& de Reuck, K. M. (eds) International Thermodynamic Tables of the Fluid State: Carbon Dioxide (Pergamon, Oxford, 1976).

13. Super, M. \& Beckman, E. J. J. Chem. Eng. Data 42, 664-670 (1997).

\section{Long-distance transport of pollen into the Arctic}

Airborne particulates can be carried over long distances, but for significant quantities of particulates larger than a few micrometres in diameter to be transported more than a few kilometres usually requires a means of injecting the material high into the atmosphere, such as a volcanic eruption, forest fire or desert windstorm. But an unusual event occurred in the Canadian Arctic last year, in which significant amounts of pine and spruce pollen $(30-55 \mu \mathrm{m}$ long) were transported roughly $3,000 \mathrm{~km}$.

On the night of 5 June 1998 and the following morning, local hunters noticed an unusual concentration of pollen at the edges of ponds on Arctic Ocean ice near Repulse Bay, Northwest Territories, Canada (Fig. 1). Similar deposits were also reported in Pelly Bay, northwest of Repulse Bay, but not in other Arctic communities. The material is a remarkably pure pollen concentrate containing $92 \%$ jack pine (Pinus banksiana) and $8 \%$ white spruce (Picea glauca). An examination of more than 1,500 pollen grains revealed no pollen from alder (the most common exotic pollen in the eastern Arctic $\left.^{1}\right)$ or other taxa, no large organic debris and no charcoal. The pollen is in excellent condition, most of it having unbroken walls and intact cytoplasm, unlike the 'yellow rain' reported in south- 